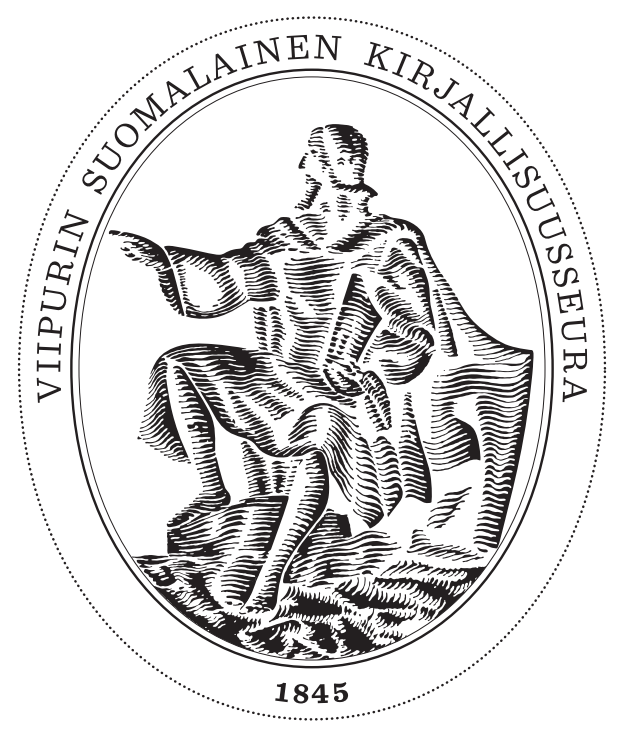

\author{
VIIPURIN SUOMALAISEN \\ KIRJALLISUUSSEURAN \\ TOIMITTEITA
}

(23)

\title{
Diasporan Viipuri
}

Muistojen kaupunki sotien jälkeen 
Kannen kuva: Postikortti 1900-luvun alusta. Yksi Monrepos'n puiston

kiinalaisista kaarisilloista. Wiipurin Arkistoyhdistys (WAY), a5a71. Wiipuri.fi.

VERTAISARVIOITU

KOLLEGIALT GRANSKAD

PEER-REVIEWED

Viipurin Suomalaisen Kirjallisuusseuran toimitteita 23

Diasporan Viipuri - Muistojen kaupunki sotien jälkeen

Toimittaneet:

Satu Grünthal (osan toimittaja)

Kristiina Korjonen-Kuusipuro (osan toimittaja)

Anu Koskivirta (sarjan päätoimittaja)

H. K. Riikonen (sarjan päätoimittaja)

lisa Aaltonen (sarjan toimitussihteeri ja kuvatoimittaja)

Taitto ja graafinen suunnittelu: Eemeli Nieminen

ISBN 978-952-69280-7-4 (sid.)

ISBN 978-952-69280-8-1 (PDF)

ISSN 1236-4304 (sarja)

Painettu: 2021, Digipaino Kirjaksi.net

Painosmäärä: $250 \mathrm{kpl}$

Ensimmäinen painos

Julkaisija: Viipurin Suomalainen Kirjallisuusseura ry, Helsinki 


\section{Viipurilainen musiikkielämä Savonlinnassa'}

Savonlinnan ja Viipurin musiikkisuhteiden juuret ovat pitkät. Niiden merkitys korostui erityisesti toisen maailmansodan jälkeen, vaikka Savonlinnasta ei tullutkaan samanlaista pikku-Viipuria kuin esimerkiksi Lahdesta, jonne siirtyi 10 ooo evakkoa ja Viipurin musiikkiopisto. Karjalaisten osuus Savonlinnan asukasluvusta oli kuitenkin merkittävä, 10-16 \% vuonna $1948 .{ }^{2}$ Joukkoon mahtui entisiä viipurilaisia, ${ }^{3}$ jotka elähdyttivät pikkukaupungin musiikkielämää.

Musiikillinen yhteistyö kaupunkien välillä oli vanhastaan tuttua, sillä Viipurin ja Savonlinnan yhteys on ollut historiallisesti kiinteä. Venäjän ja Ruotsin rauhanteossa vuonna 1743 Savonlinna ympäristöineen jäi Venäjän puolelle rajaa, ja siitä tuli osa Viipurin kuvernementtiä. Liikkumista edistivät Saimaan kanava (1856) ja Elisenvaaran rata (1908). Ennen omaa lyseota (1884) Savonlinnasta mentiin lukioon Kuopioon tai Viipuriin. Samoin paikalliset muusikot saivat lisäoppia Viipurissa tai Pietarissa. ${ }^{4}$ Tiiviistä yhteyksistä hyötyivät pitkällä aikavälillä käsi kädessä kulkeneet matkailu ja kulttuuri.

\section{Kansainväliset oopperajuhlat}

Varhaiset oopperajuhlat syntyivät Savonlinnaan tunnetusti Aino Acktén (1876-1944) ponnistelujen ansiosta. Ackté oli ihastunut Olavinlinnaan, seudun luontoon ja ihmisiin, mutta merkityksellisiä olivat yhteydet Viipuriin ja Pietariin.

Savonlinnan oopperajuhlia edelsi Viron laulujuhlista inspiroitunut kotimaisten musiikkijuhlien sarja. Viipurin laulujuhlista (1908) Ackté sai lopullisen kimmokkeen perustaa oopperajuhlat. Vaikka Savonlinnan ensimmäisten oopperajuhlien (1912) ohjelmisto oli ajan hengen mukaan suomalaista, Ackté tähtäsi kansainvälisyyteen. Tämän mahdollisti muun muassa Savonlinnan ja Pietarin välillä kolmesti viikossa kulkeva laivayhteys.

Savonlinnalla oli vilkas kuoroelämä, ja Soittokunnan kannatusyhdistys oli perustettu $1904{ }^{5}$ Oopperajuhlille haluttiin kuitenkin Suomen suuriruhtinaskunnan tasokkaimmat soittajat Helsingin Filharmoonisesta Seurasta ja Viipurin orkesterista. Myös laulajien joukossa oli viipurilaisia; ensimmäisillä juhlilla Aino-oopperan miespääosaa esitti Adolf Niska (1884-1960), joka oli opiskellut muun muassa Milanossa ja Berliinissä. Ainon osassa esiintyi Aino Ackté. Aino-oopperan säveltäjä Erkki Melartin (1875-1937), entinen Savonlinnan lyseolainen, oli perustanut orkesterikoulun Viipuriin vuonna 1909. Melartin johti vuoden 1912 juhlien avajaisesityksen ja vieraili juhlilla myöhemminkin. ${ }^{6}$

Viipurin jo varhain monikansalliseksi muotoutunut musiikkielämä7 heijastui oopperajuhliin tilanteessa, jossa maan orkesteriväki oli jakautunut kahtia: suomenmielisen Kotimaisen Orkesterin johtajana toimi Robert Kajanus, kun taas viipurilaissyntyisen kapellimestari Georg Schnéevoigtin orkesteri koostui ulkomaisista soittajista. Aino Ackté liittoutui Schnéevoigtin kanssa ja luotsasi oopperatoimintaa niin Savonlinnassa kuin Helsingissäkin monikieliseen ja kansainväliseen suuntaan. ${ }^{8}$

Viipurilaiset oopperavieraat tekivät pakettimatkoja junalla Savonlinnaan ja takaisin Viipuriin 
Imatran Vallinkosken kautta. ${ }^{9}$ Oopperajuhlat lisäsi viipurilaisten ja savonlinnalaisten kanssakäymistä niin esiintyjien kuin yleisönkin välillä.

Vaikka oopperajuhlat hiipuivat ja II maailmansota katkaisi yhteistyön, kansainvälinen linja jatkui Savonlinnan musiikkipäivillä vuodesta 1955 lähtien. Sodanjälkeisessä tilanteessa nuoret muusikot eivät päässeet ulkomaille opiskelemaan, joten Yrjö Kilpinen päätti järjestää korkean tason musiikillista jatkokoulutusta Savonlinnassa erityisesti saksankielistä musiikkimaailmaa edustavien opettajien johdolla. Vastaavia kursseja ei muualla Suomessa ollut. ${ }^{10}$

Suuntautuminen saksankieliseen musiikkikulttuuriin näkyi myös Savonlinnan uudelleen perustetuilla oopperajuhlilla vuonna 1967. Uuteen kukoistukseen juhlat nosti Hiitolassa syntynyt, Viipurin musiikkiopistoa Lahdessa käynyt ja Savonlinnassa opettajaksi valmistunut Martti Talvela, joka tunnettiin oopperalaulajana myös ulkomailla. ${ }^{11}$

\section{Musiikki yhdisti evakot}

Aiemmat yhteydet helpottivat viipurilaisten solahtamista Savonlinnaan sotien jälkeen. Sopeutumisessa auttoi yhdessä musisointi. Talvisodassa pommitetun Tuomiokirkon tilalle evankelilaisluterilainen seurakunta hankki aiemmin ortodoksisen Pikkukirkon, jonka 12-henkisestä kirkkokuorosta vastasivat evakot kanttori Hannes Haapion johdolla. Haapio oli valmistunut Viipurin kirkkomusiikkiopistosta ja toiminut muun muassa laulunopettajana Viipurin klassillisessa lyseossa. Kuorolla oli tärkeä sosiaalinen merkitys, sillä tapaamiset sisälsivät laulamisen ohella kotiseudun muistelua ja vertaistukena toimimista. Lisäksi kulttuurinnälkä sodan jälkeen pienellä paikkakunnalla oli valtava. ${ }^{12}$ Vuonna 1945 kirkkokuorosta eriytyi naiskuoro Karjalaiset Naiset, myöhempi Savonlinnan Naiskuoro, joka vuonna 1954 liittyi Sulasoliin sekä Suomen Naiskuoroliittoon ja saavutti menestystä kansallisissa kuorokilpailuissa ja -katselmuksissa, vaikka nimenmuutos aiheuttikin jännitteitä. Viipurilaisten lisäksi laulajia oli Viipurin maalaiskunnasta, Sortavalasta, Sortavalan maalaiskunnasta, Heinjoelta, Kurkijoelta, Muolaasta, Ruskealasta, Hiitolasta, Sakkolasta ja Terijoelta sekä sittemmin myös muualta. Jäsenmäärä oli suurimmillaan 1950-luvulla, jolloin laulajia oli yli 50. Anneli Karvanen (os. Kurola, s. 27.11.1927 Viipurissa) on yhä edelleen, 2020-luvun alussa, kuoron "syän"13

Monet entiset viipurilaiset jatkoivat musiikkiharrastuksiaan Savonlinnassa. Myöhemmin terveydenhoitajana toiminut Salme Toikkanen (os. Niiranen, s. 8.8.1924 Viipurissa) kertoi perheessään Viipurin Loikkasessa soitetun pianoa, lauletun ja pidetyn kirkkokuoron harjoituksia. Myös konserteissa käytiin. Savonlinnassa hän kävi vuosina 1945-1946 pianotunneilla terijokelaisen, venäläissyntyisen emigranttinaisen luona Tottin talossa Satamakadulla ja jatkoi erityisesti kirkkokonserteissa käyntiä. ${ }^{14}$

Tuulahdus vanhan Viipurin loistokkaasta musiikkielämästä koettiin 1970-luvun lopulla, kun legendaarinen Heimo Haitto (1925-1999) päätti Amerikan kulkurinvuotensa ja asettui Savonlinnan musiikkiopiston viulunsoiton lehtoriksi. ${ }^{15}$ Haitto oli Viipurin musiikkiopiston perustaja Boris Sirpon ${ }^{16}$ oppilas, joka voitti kansainvälisen viulukilpailun Lontoossa vain 13-vuotiaana. Sittemmin hän toimi muun muassa konserttimestarina New Yorkin Metropolitanissa, kunnes jätti kaiken ja ryhtyi kiertolaiseksi. ${ }^{17}$ Savonlinnassa hän löysi jälleen viulunsoiton ja esiintyi Haitto Trion, 
Savonlinnan kamariyhtyeen, Pentti Savolaisen sekä toisen vaimonsa, Eva Vastarin (1922-2008), kanssa. Haitto oli mustassa baskerissaan mieliinpainuva ilmestys ja keräsi ympärilleen entisiä viipurilaisia ja Viipurin musiikkiopistolaisia muistelemaan menneitä. ${ }^{18}$

Viipurin läänistä kehkeytyi 1800-luvulla romanien runsain asutuskeskittymä. Vielä 1900-luvun alussa kolmannes silloisen Suomen noin 2000 hengen suuruisesta romaniväestöstä asui Viipurin läänissä. Romani-identiteettiin kuuluivat olennaisesti suullisena perinteenä siirtynyt musiikki, jossa näkyvät myös yhteydet valtaväestön musiikkiin, sekä karjalaisuus. Muiden tavoin myös romanievakot lähtivät Savonlinnasta kotiseutumatkoille Viipuriin heti rajojen avauduttua. ${ }^{19}$ Sen sijaan tutkimusta romanien musiikkiperinteestä uudella kotipaikkakunnalla on vähän. ${ }^{20}$ Karjalaistaustaisen romaniväestön, heidän musiikkiperinteensä ja kulttuurinsa laajempi tunnustaminen osana karjalaisuutta - samoin kuin karjalaisuuden osana romanikulttuuria - avaisi uusia näkökulmia karjalaisuuteen ja Viipurin musiikkielämän diasporaan.

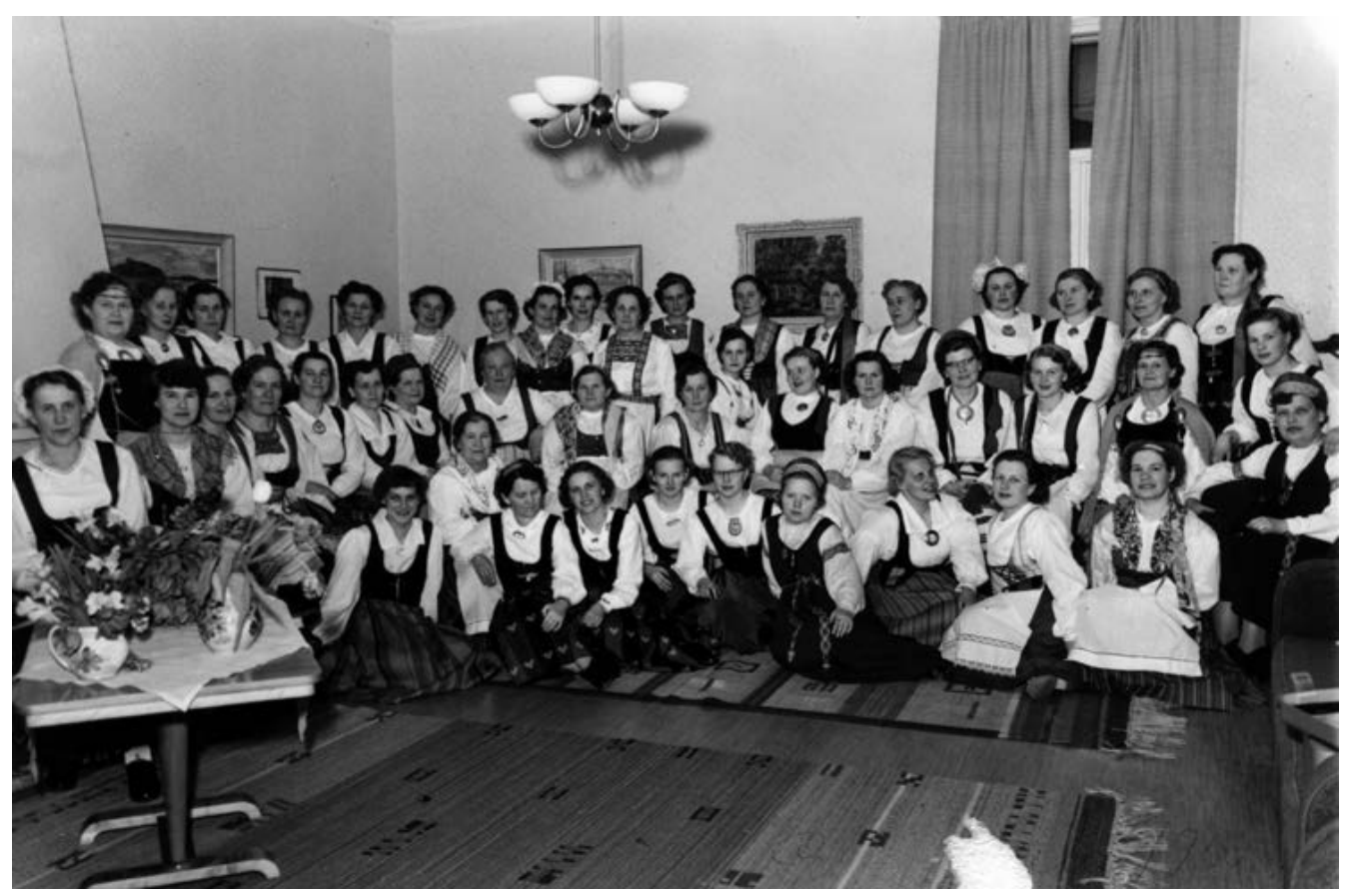

Naiskuorolaiset viettämässä pikkujoulua vuonna 1954 Mirjam Miettisen kotona Savonlinnassa. Osalla kuorolaisista oli juhla- ja esiintymisasuina karjalaiset kansallispuvut, osalla muun Suomen kansallispukuja. 
Viitteet

1 Tämä tietolaatikko on syntynyt Suomen Akatemian ja Jyväskylän yliopiston rahoittaman projektin, Lamemoli no. 307635, 2017-2021, yhteydessä.

2 Hytönen 2006, 44; Savonlinnan asukasluku vuonna 1948 oli 10 851. Suomen tilastollinen vuosikirja 1948, 1949, 11.

3 Viipurilaisia asui Savonlinnassa 605 vuonna 1946, Paukkunen 1989, 35

$4 \quad$ Kuokkanen 1934; Helasvuo 1990, 57.

5 Vuodesta 1915 Soitannollinen Seura. Savonlinnan orkesteriyhdistys, 1985.

6 Savolainen 1995, 30, 51-55.

7 Pajamo 2018, 23-51.

8 Savolainen 1995, 42-44.

9 "Ooppera-, laulu- ja soittojuhlat Savonlinnassa 3.-7.7. 1912", Savolainen 4.7.1912 (no $71 \mathrm{~B}$ ).

10 Savolainen 1995, 71.

11 Heikinheimo 1978; Hako 2004; Savolainen 2007.
12 Anneli Karvasen puhelinhaastattelu 8.2.2020.

13 Savonlinnan Naiskuoron arkisto. Haltija: Anneli Karvanen, Savonlinna. Jäsenluettelo, Eila Niirasen puhe Savonlinnan Naiskuoron 30-vuotisjuhlakonsertissa ja Eila Niirasen tekemä Anneli Karvasen haastattelu 24.6.2018, 78.

14 Susanna Niirasen perhearkisto. Salme (Maija) Toikkasen haastattelu 10.2.2019.

15 Paajanen et al 2007, 140.

16 Käytti myös muotoa Sirob. Alun perin ossetialaissyntyinen Boris Osipovitš Wolfson.

17 Haitto \& Vastari 1995.

18 Viipurin musiikkiopistossa viulunsoittoa opiskellut kirjoittajan äidinpuoleinen isoisä Otto Manninen (1911-1991) tapasi Heimo Haittoa Savonlinnassa. Susanna Niirasen perhearkisto. Muistitieto.

19 Åberg, 2018.

20 Åberg 2002; Åberg 2003. 
Lähde- ja kirjallisuusluettelo

\section{Arkistolähteet ja haastatteluaineisto}

Anneli Karvasen puhelinhaastattelu 8.2.2020. Haltija: Susanna Niiranen, Jyväskylä.

Savonlinnan Naiskuoron arkisto. Haltija: Anneli Karvanen, Savonlinna.

Susanna Niirasen perhearkisto. Jyväskylä \& Savonlinna.

Sanomalehdet

Savolainen, no 71 B (1912). Kansalliskirjaston digitaaliset aineistot (https://digi.kansalliskirjasto.fi).

Painetut lähteet ja tutkimuskirjallisuus

Haitto, Heimo \& Vastari, Eva (1995). Viuluniekka kulkurina. Heimo Haiton vaellusvuodet Yhdysvalloissa 1965-76. Helsinki: Tammi.

Hako, Pekka (2004). Unohtumaton Martti Talvela: Elämäkerta. Helsinki: Gummerus/Ajatus.

Heikinheimo, Seppo (1978). Martti Talvela: Jättiläisen muotokuva. Helsinki: Otava.

Helasvuo, Veikko (1990). "Paljasjalkalaisen savonlinnalaisen muisteluksia musiikista ja vähän muustakin". Teoksessa Rakas Savonlinna. Itäsavolaisia kulttuurikuvia, toim. Paavo Harju et al. Helsingin Savonlinna Seura, 55-61.

Hirn, Sven (2006). "Niska, Adolf". Kansallisbiografia-verkkojulkaisu. Studia Biographica 4. Helsinki: SKS. (http://urn.fi/urn:nbn:fi:sks-kbg-003284, viitattu 5.12.2019)

Hytönen, Tiina (2006). Sodanjälkeisen asutustoiminnan vaikutus Suomen väestökehitykseen. Pro gradu -tutkielma. Jyväskylä: Jyväskylän yliopisto.

Kuokkanen, Aimo (1934). Savonlinnan lyseo 1884-1934: historiikkeja, koulumuistelmia, opettaja- ja oppilaselämänkertoja. [Kustantaja tuntematon].

Laitinen, Erkki (1995). "Vuoden 1945 maanhankintalain synty, sisältö ja toteutus". Teoksessa Rintamalta raivioille - Sodanjälkeinen asutustoiminta 50 vuotta, toim. E. Laitinen. Jyväskylä: Atena, 52-137.

Paajanen, Maunu et al. (toim. 2007). Musiikille. Savonlinnan musiikkiopisto 50 vuotta. Savonlinnan musiikkiopisto 1957-2007. Savonlinna: Savonlinnan musiikkiopisto.

Pajamo, Reijo (2018). Musiikin juhlaa Wiipuris. Helsinki: Repale-kustannus.

Paukkunen, Leo (1989). Siirtokarjalaiset nyky-Suomessa. Jyväskylän yliopiston yhteiskuntapolitiikan laitoksen tutkimuksia A5. Jyväskylä: Jyväskylän yliopiston yhteiskuntapolitiikan laitos.

Savolainen, Pentti (1995). Balladi Olavinlinnan oopperajuhlista. Helsinki: WSOY.

Savolainen, Pentti (2007). Martti Talvela: Elämän valoja ja varjoja. Helsinki: WSOY.

Savonlinnan orkesteriyhdistys (1985). Savonlinnan soitannollinen seura, Savonlinnan orkesteriyhdistys 1915-1985. Savonlinna: Savonlinnan orkesteriyhdistys.

Suomen tilastollinen vuosikirja 1948 (1949). Helsinki: Valtioneuvoston kirjapaino.

Åberg, Kai (2018). "Karjalan kaaleet (romanit) osana itäsuomalaisuutta - 100 vuoden hiljaisuus". Musiikinsuunta 1/2018. Helsinki: Suomen Etnomusikologinen Seura. (http://musiikinsuunta.fi/2018/01/ karjalan-kaaleet-osana-itasuomalaisuutta/, viitattu 28.11.2019)

Åberg, Kai (2002). "Nää laulut kato kertoo meijän elämästä" - Tutkimus romanien laulukulttuurista 1990- luvulla. Helsinki: Suomen etnomusikologinen seura.

Åberg, Kai (2003). Romanilauluja Itä-Suomesta. Helsinki: SKS. 


\section{Kuvalähteet}

s. 15 Valokuvat ja kollaasi: Kristiina KorjonenKuusipuro.

s. 26 Kartta: Eemeli Nieminen

s. 45 Valokuva: E. M. Staf. Teatterimuseon arkisto. 07032459001.

s. 51 Valokuva: Matti Pukkila. Teatterimuseon arkisto. 97082002

s. 52 Valokuva: Matti Pukkila. Teatterimuseon arkisto. 99027157

s. 53 Valokuva: Matti Pukkila. Teatterimuseon arkisto. 99027156.

s. 55 Valokuva: Eino Nieminen. Teatterimuseon arkisto. 07032783002

s. 58 Valokuva: Yrjö Huittinen. Teatterimuseon arkisto. 99028042.

s. 60 Valokuva: tuntematon. Satu Grünthalin yksityisarkisto

s. 62 Valokuva: Tapio Hartikainen. Teatterimuseon arkisto. 96046006

s. 81 Valokuva: Valokuvaamo L. Jänis.

s. 99 Valokuva: Jani Karhu.

s. 106 Valokuva: Pauli Ukkonen.

s. 122 vas. 1950-luvun kuva Hilda ja Urho Härmän albumi, Päivi ja llkka Kuivalaisen yksityisarkisto.

s. 122 oik. Vuoden 2021 valokuva: Kristiina Korjonen-Kuusipuro.

s. 130 Valokuva: Seppo Pelkonen. Lappeenrannan museot.

s. 140 Pertti Jarlan yksityisarkisto. s. 189 Kuva teoksesta Elävää historiaa: peruskoululaiselle (1986)

s. 191 Kuva teoksesta Peruskoulun historia: 4 Työkirja (1975)

s. 193 Kuva teoksesta Keskikoulun Suomen historia (1950).

s. 205 ylh. kuva teoksesta Karjalan yhteiskoulu. Viipurin uusi yhteiskoulu 1905-1965 (1965).

s. 205 alh. Lappeenrannan museot. WMWE226:1.

s. 239 Valokuva: Juho Vikstedt. Lahden kaupunginmuseo. LHMVHMLV10338:1183 MVHMLV10338_1183.

s. 240 Valokuva: Leo Nevalainen.

s. 246 oik. Wikimedia Commons.

s. 246 vas. Kansallisarkisto.

s. 258 Выборгский объединенный музейзаповедник (ВОМЗ). Выборг. [Viipurin museotoimi.]

s. 261 Выборгский объединенный музейзаповедник (ВОМЗ). Выборг. [Viipurin museotoimi.]

s. 263 Выборгский объединенный музейзаповедник (ВОМЗ). Выборг. [Viipurin museotoimi.]

s. 281 Valokuva: Ebbe Linde. Svenska litteratursällkapet i Finland. SLSA 566_386.

s. 296 Valokuva: tuntematon. Svenska litteratursällkapet i Finland. SLSA 566_es25.

s. 303 Museoviraston kirjasto.

s. 316 Museoviraston kirjasto. 